\title{
Detection of cracks in laser deposited coatings by laser spot thermography
}

\author{
by Piotr Koruba*, Jacek Reiner* and Adrian Zakrzewski* \\ *Wroclaw Univ. of Technology, Wyb. Wyspianskiego 27, 50-370 Wroclaw, Poland, piotr.koruba@pwr.edu.pl
}

\begin{abstract}
Coatings deposited by laser cladding are characterized by high hardness and extended wear, chemical or thermal resistance. However, inappropriate process parameters or material incompatibility can result in generation of stress that cause coating crack. Since it is a critical fault, such coatings are tested with NDT methods such as PT or MT. This paper presents the outcome of crack detection in metallic coatings with laser spot thermography. The research was conducted with various imaging systems and two laser sources with different wavelengths. The influence of imaging and excitation systems parameters on the inspection sensitivity and robustness to disturbances that arise from inhomogeneous surface were presented.
\end{abstract}

\section{Introduction}

Nowadays laser cladding technology is widely used as method of coatings deposition, repair of worn out machine parts and additive manufacturing [1]. Surface cracks are considered to be a critical issue for laser deposited clads. Such defects are regarded as notches that can weaken the strength of coating material or reduce its corrosion protection. These flaws arise due to stresses that were caused by high temperature gradient or difference of thermal expansion coefficients of the clad material and the substrate [2]. To detect such cracks of width less than 50 $\mu$ m nondestructive testing methods as penetrant testing PT and magnetic testing MT are commonly used. Nevertheless, these methods have contact character and are quite time-consuming, so an alternative form of quality control are being searched for. Many authors regard the active thermography as alternative NDT approach, which fulfill foregoing expectations of non-contact and fast control $[3,4,5,6]$. The methods of active thermography such as lock-in or pulse thermography are widely used for example to detect delaminations, porosity and inhomogenities of composite materials in aerospace industry $[7,8]$.

However, a great amount of amenable parts is still made of metal alloys that are characterized by low emissivity and high reflectivity, which makes them difficult to inspect. For instance in [9] authors used black paint coating to achieve uniform and higher emissivity of the specimen surface. In case of metallic elements following methods are mentioned: vibrothermography, eddy currents excitation or laser spot thermography [4]. In [3] it was reported, that laser spot active thermography allowed detecting defects of a very small size: $5 \div 10 \mu \mathrm{m}$ wide, although the presented examples dealt with cracks of width larger than $50 \mu \mathrm{m}$. Authors in [10] indicates that the thermal contrast of the crack in the image from the camera is dependent on defects depth and for eddy currents method they estimate the lower limit to $200 \mu \mathrm{m}$. On the other hand the use of laser spot thermography has allowed detecting artificial flaws $10 \div 30 \mu \mathrm{m}$ deep and with widths about $80 \mu \mathrm{m}[11]$.

Nonetheless, the size of cracks that occur during laser cladding process is still smaller than examples mentioned above. Moreover, one of the most crucial factor that determines the sensitivity of the laser spot method is surface topography, which in case of laser cladding before the finishing treatment, is anisotropic. Perpendicularly to the cladding direction the surface is characterized with large heterogeneity of roughness, especially on the hollows between subsequent single clads. These surface deviations might be considered as additional noise on thermographic image. Therefore, it can be expected, that these areas of coating may be particularly problematic for inspection.

This paper presents the results of crack detection in laser deposited clads by using laser spot thermography. The investigations were conducted with various imaging systems and two laser sources with different wavelengths $\mathrm{CO}_{2}$ and $\mathrm{Nd}$ :YAG were used to provide the thermal energy by scanning the specimen. The influence of parameters of imaging and excitation systems on the inspection sensitivity and the robustness of disturbances that arise from inhomogeneous surface were shown.

\section{Theory}

According to [12] during the thermographic inspection of metallic surface the increase in observed temperature $T$ as the laser spot passes over a defect corresponds to change in emissivity. This deviation can be explained by using simple model of elongated conical shape notch (Fig. 1a). The effective emissivity $\varepsilon_{\text {eff }}$ of this geometry may be determined based on the method shown in [13]. The basic principle of this approach is to calculate power radiated by the body as it is described by Stefan-Boltzmann law and then to compare it with hypothetical emitting surface (Eq. 1). However in this model multiple reflections on the inner conical surface are ignored and only radiative heat transfer is assumed. In the calculation $\varepsilon$ is material emissivity and $\rho$ its reflectivity. 


$$
\varepsilon(1+\rho) \sigma T^{4}=\varepsilon_{\text {eff }} \sigma T^{4}
$$

a)

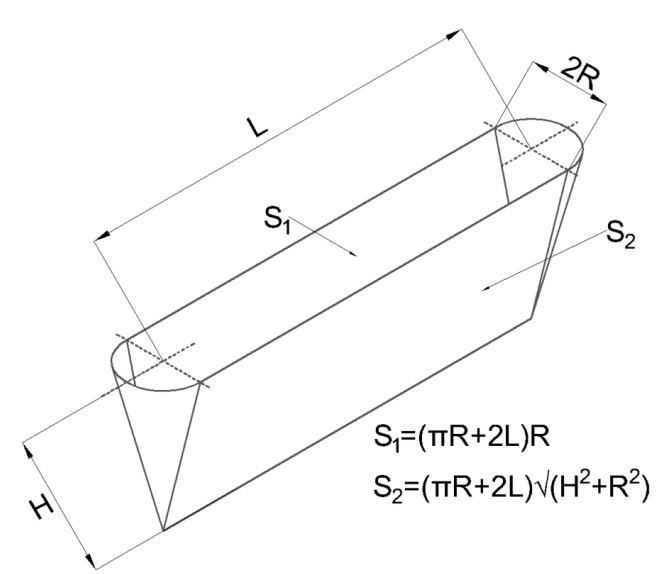

b)

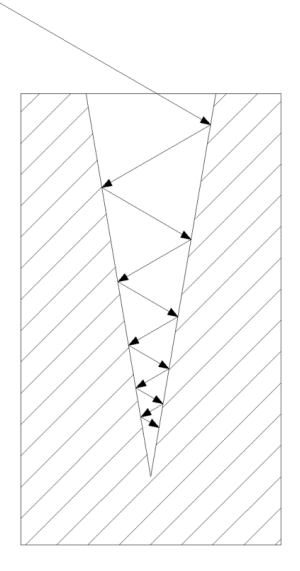

Fig. 1. Simplified conical model of the surface defect: dimensions (a), multiple reflection phenomenon (b)

In order to determine the effective emissivity of surface geometry one should calculate corresponding view factors and surface areas $\left(S_{1}\right.$ or $\left.S_{2}\right)$. The method is widely described and discussed in [13] or [14], so here it is limited to final equation (Eq. 2) that combines the material properties $\varepsilon$, width $2 R$ and depth $H$ of the notch with effective emissivity that is observed by the thermal camera.

$$
\varepsilon_{e f f}=\frac{\varepsilon}{1-(1-\varepsilon)\left(1-\frac{1}{\sqrt{1+(H / R)^{2}}}\right)}
$$

Generally the effective emissivity grows with the increase of depth to width ratio $H / R$. This means that defects can be described as local growth of surface emissivity what results in higher temperature observation - hot spots. The result (Eq. 2) has been also depicted in the Fig. 2. It should be noticed that even with average value of material emissivity and high depth to width ratio $\varepsilon_{\text {eff }}$ could almost double.

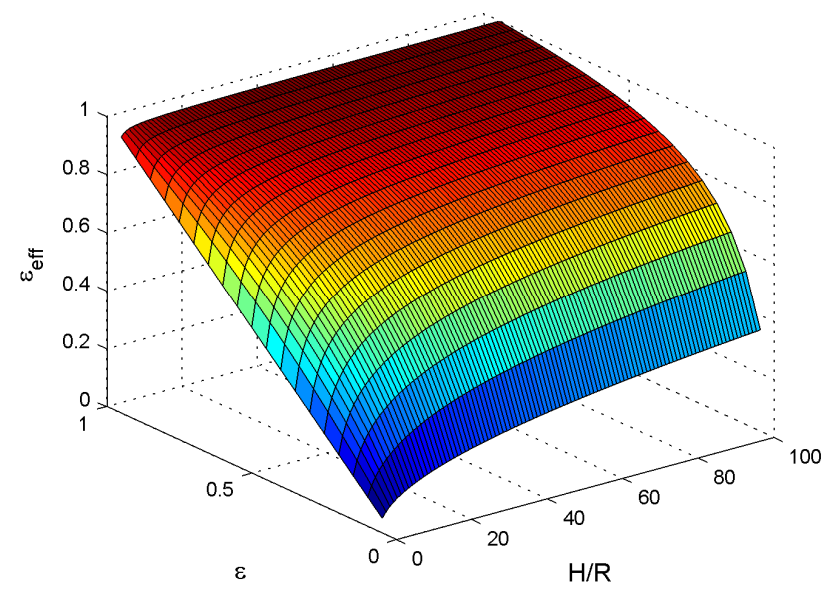

Fig. 2. Effective emissivity ( $\left.\mathcal{E}_{\text {eff }}\right)$ dependency on material emissivity $(\varepsilon)$ and depth to width ratio $(H / R)$

In the approach shown above simple model without multiple reflections of the inner surface of the defect was discussed. However it should be indicated that so called surface development results in reduction of reflectivity coefficient since the absorption of the irradiation strongly increase (Fig. 1b). In this situation the probability that irradiation leaves out the cavity is marginal to the probability of being absorbed. This phenomenon concerns also high reflecting materials such as metals and leads to black body imitation that is widely used in praxis [15]. To achieve such result the 


\subsection{1/qirt.2016.064}

thermal camera should be focused on the virtual surface in the entrance to the cavity [13]. Furthermore, significant surface roughness can lead to the same effects of increasing the emissivity coefficient. In case of real crack all discussed phenomenon should be combined which may result in black body approximation that is suggested in [3].

\section{Experiment setup}

The whole experiment was divided into four stages: preparation of laser cladding samples with and without flaws, creating artificial defects on some coatings, measuring defects using 3D microscopy and finally laser spot thermography tests. The IR camera that has been used for thermal measurements was FLIR SC7500 (320x256 InSb detectors matrix) with pixel pitch $30 \mu \mathrm{m}$. Further, two different imaging systems for the camera: standard $50 \mathrm{~mm}$ lens and close up $x 1$ macro lens were used. The measurements were carried out on the NiCrBSi alloy coating that was deposited on AISI 4330 steel substrate. The coatings were created using HPDL diode laser $(\lambda=900-1030 \mathrm{~nm})$ with power $450 \mathrm{~W}$ and additional preheating of the substrate. The prepared samples were in the form $30 \times 30 \mathrm{~mm}$ coatings. In order to achieve coating with flaws, the temperature of the substrate has been decreased for some specimens (figure 3 ).

a)

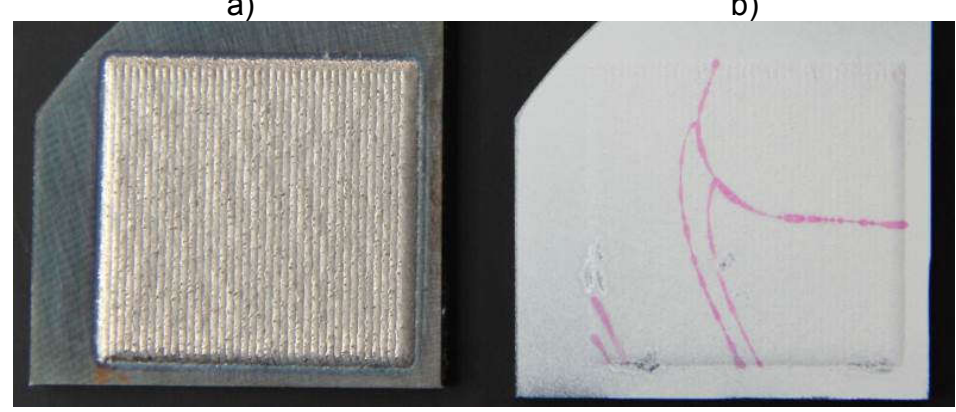

Fig. 3. Laser deposited coatings: before (a) and after PT test (b)

Reference samples on some coatings artificial defects have been prepared in the shape of notch by laser ablation using picosecond Nd:YAG laser. These flaws have been prepared with different process parameters such as: number of laser scans and focus distance. Parameters such as pulse length and repetition were constant and stand respectively at $1 \mathrm{ps}$ and $100 \mathrm{kHz}$, All of the coatings were examined through scanning topographical structure with confocal microscope to identify flaws width. Moreover defects that were created by micromachining have been separated into two group depending on the laser beam focusing. Fig. 4 shows that for artificial defects the width range was about $30 \div 70 \mu \mathrm{m}$, whereas the size of natural flaws was less than $30 \mu \mathrm{m}$. It is important to note, that for visible light camera with pixel pitch $30 \mu \mathrm{m}$ and close up $\mathrm{x} 1$ lens such small objects might not be observed without using dark field microscopy [16].

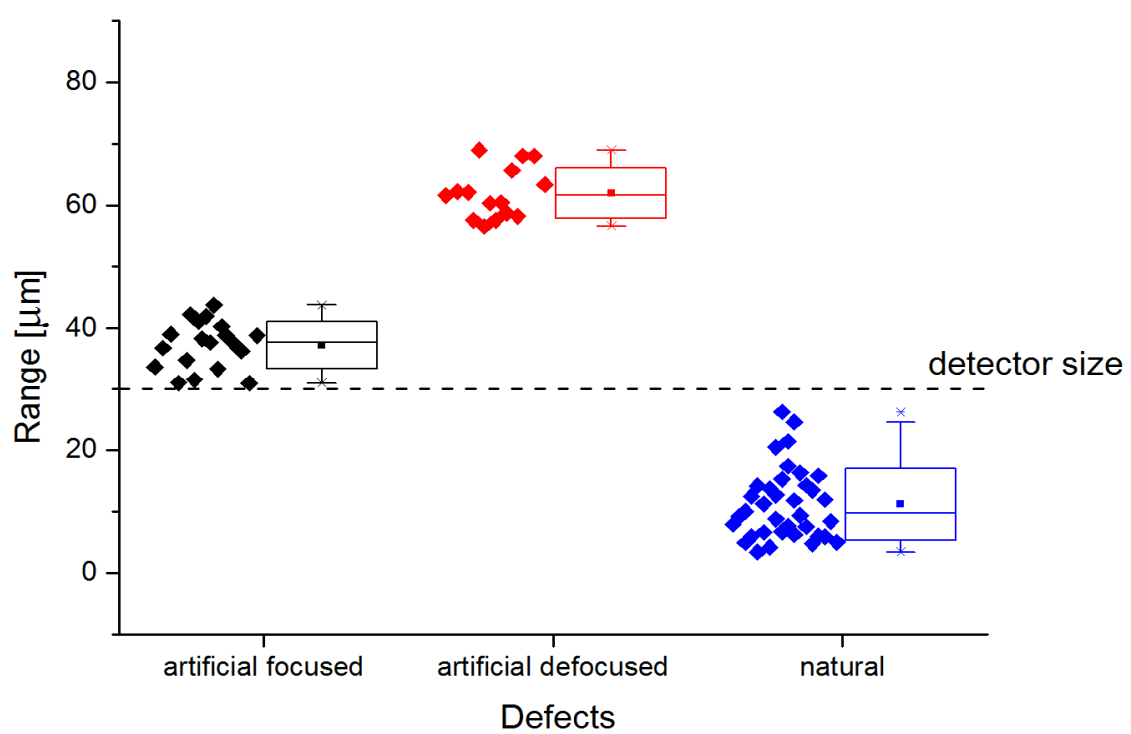

Fig. 4. Width distribution of artificial and natural defects on cladding surface

The depth of both artificial and natural defects was examined with scanning electron microscope ZEISS EVO MA 25. For artificial flaws measured depth was about $120 \div 250 \mu \mathrm{m}$ and depended on number of laser scans. In contrast, the measurements of natural defects depth shows a vast dispersion from 10 to even $500 \mu$ m. However the edges of cracks have irregular shape and thus obtained results might be understated. Besides, inside the defects obstacles such 
as semi-melted powder particles can be found and this also impede depth measurements. The images of exemplary both artificial and natural defects are shown in figureFig. $5 a \div b$.

a)

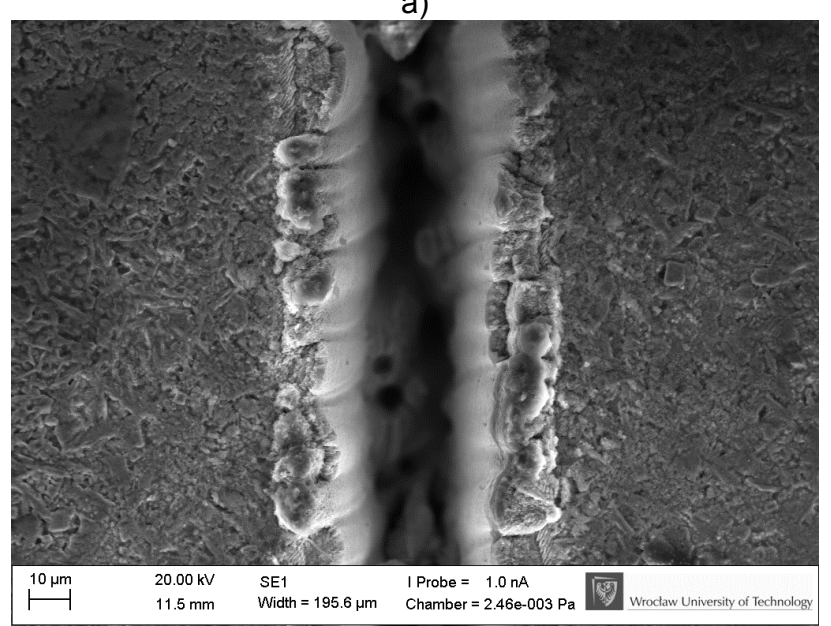

b)

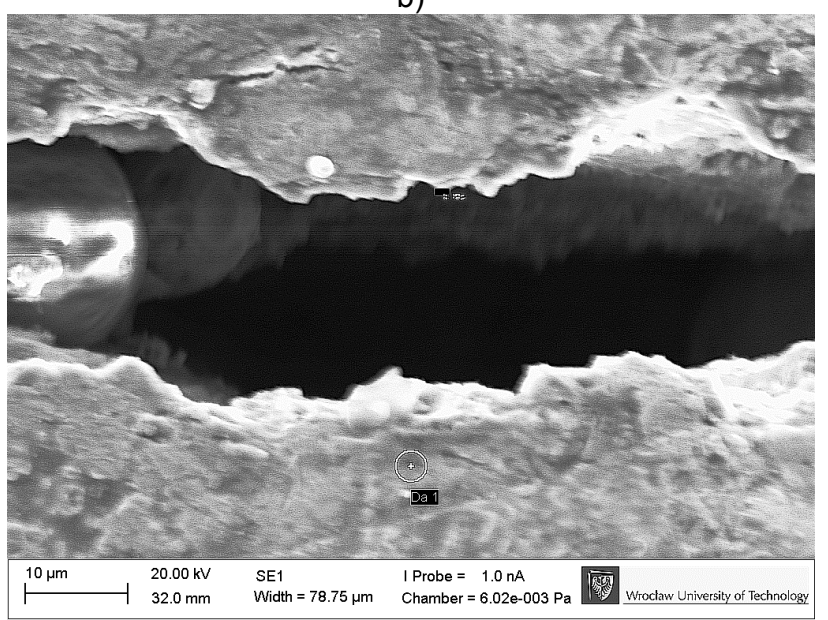

Fig. 5. The images received by electron microscopy: artificial (a) and natural defect (b)

Measurement of such small objects as cracks requires a discussion about spatial resolution of used optical system. The spatial resolution of the thermal camera is defined by two parameters IFOV (Instantaneous Field Of View) and FOV (Field Of View) [13]. These parameters can be derived from simple geometrical dependencies (Eq. 3) and (Eq. 4 ), where $D$ is the size of the object that corresponds to single detector in the thermal camera, $d$ is the distance from the object to the camera, $D_{\text {det }}$ is the detector size, $f_{o b}$ is the focal length of used lens and $n_{\text {pix }}$ is the number of pixel in the investigated direction.

$$
\begin{gathered}
I F O V=2 \arctan \left(\frac{D}{2 d}\right) \approx 2 \arctan \left(\frac{D_{\mathrm{det}}}{2 f_{o b}}\right) \\
I F O V=\frac{F O V}{n_{p i x}}
\end{gathered}
$$

For SC7500 camera with $50 \mathrm{~mm}$ lens IFOV is equal to $0.6 \mathrm{mrad}$ what for distance d equals about $200 \mathrm{~mm}$ results in the smallest detectable object size of $120 \mu \mathrm{m}$. However, for practical use it is generally accepted to use doubled value of IFOV to determine the limit of object detectability, thus it size need to be greater than $240 \mu \mathrm{m}$. Nonetheless, discussion above concerns the situation related to visual camera measurement.

The measuring system (figure 6) consists of several types of excitation sources such as $\mathrm{CO}_{2}$ laser $(10.6 \mu \mathrm{m})$ $25 \mathrm{~W}, \mathrm{Nd}$ :YAG laser (1.064 um) $15 \mathrm{~W}$ and flash lamp $6 \mathrm{~kJ}$, where the last two were used just for comparison to the $\mathrm{CO}_{2}$ laser. During the excitation, the thermal camera was mounted in such a way that it observed the sample at an angle of $45^{\circ}$.

a)

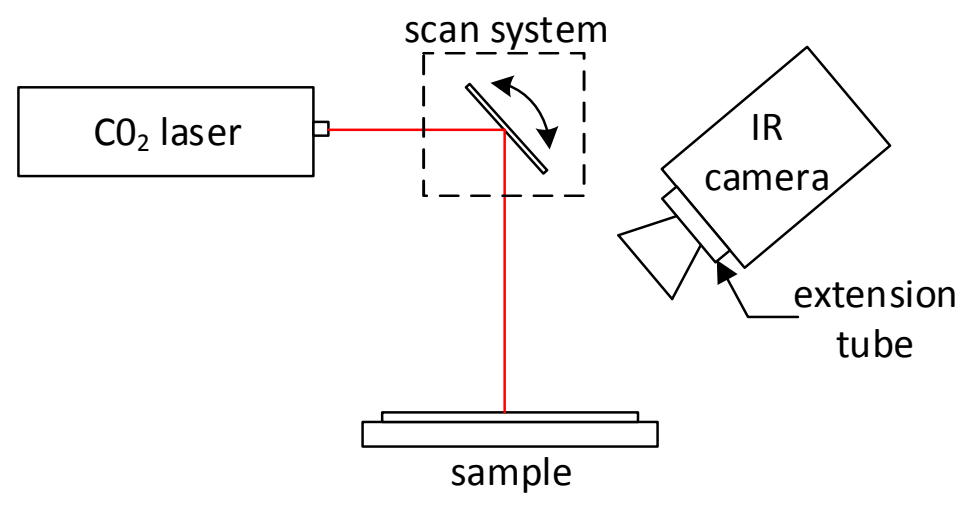

b)

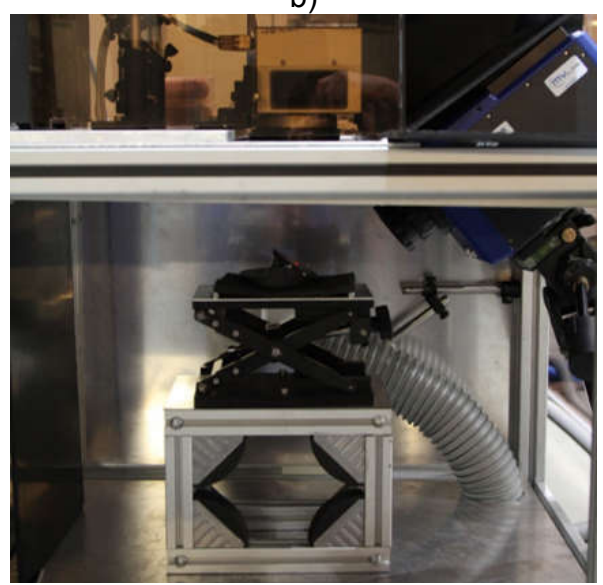

Fig. 6. Measurement system for laser spot thermography: schematic diagram (a) and actual realization (b) 


\subsection{1/qirt.2016.064}

Laser excitation of the specimen surface was realized by galvo scanners, which made it possible to use standard $50 \mathrm{~mm}$ lens as well as close up $\mathrm{x} 1$ lens for the thermal camera. The $50 \mathrm{~mm}$ objective with additional extension tube was used during the thermal imaging for resolution improvement up to few or several micrometers per pixel. This extension tube was mounted between the objective and the camera. Using thin lens approximation, the registered object $o$ and image $i$ are related by the equation (Eq. 5) in the case when the objective is created by single lens with focal length $f$ :

$$
\frac{1}{f}=\frac{1}{o_{1}}+\frac{1}{i_{1}}
$$

where: $o$ - distance between object and objective, $i$ - distance between objective and camera's photodetectors , $f-$ objective focal length. Since the optical system magnification is defined by following equation:

$$
m_{1}=\frac{i_{1}}{o_{1}}
$$

The distance between objective and camera increases when extension ring is used:

$$
i_{2}=i_{1}+L
$$

where: $L$ is the length of extension ring. Hence, the magnification can be described as:

$$
m_{2}=\frac{i_{2}}{o_{2}}+m_{1}+\frac{L}{f}
$$

Finally, the magnification due to the addition of the extension ring characterized by $L$ length is:

$$
m_{L}=\frac{m_{2}}{m_{1}}
$$

In the one hand, the application of extension tubes allows changing the effective focal length, it means magnification or FOV. But, on the other hand, this solution diminish the aperture (sensitivity of the detector) and introduces temperature distortions which are visible on the figure $12 b$ as a different temperature region outside the central area. It results from the heating of the ring as it has been proven in the paper [17]. The extension tubes have influence on the measurement system configuration and are themselves a source of additional radiation which reaches the detector array. The area diameter of properly recorded temperature decreases with increasing the length of the tube. Furthermore, when the extension is used then the focal plane is closer to the lens of the objective. Hence, this can lead to a negative situation when the focal plane will be located inside the objective effectively prevent to obtain a sharp image quality.

Moreover, authors of [18] emphasize also negative impact of extension tubes on temperature determination due to emerging uncertainties. This fact is described as a result of decreasing FOV and infrared radiation losses.

\section{Results and discussion}

In this section the results of flying laser thermography has been presented. In order to find the limit of the $\mathrm{CO}_{2}$ laser excitation method a designed experiment was carried out. The optics used for those tests was close up $\mathrm{x} 1$ lens. Afterwards there have been some attempts with standard $50 \mathrm{~mm}$ lens performed during which different types of excitation was used: step, vertical and horizontal scanning. Before the tests with laser excitation source the reflected temperature and emissivity of the coating material were experimentally determined. The values of these parameters were assessed at $23.5^{\circ} \mathrm{C}$ for $T_{\text {reft }}$ and 0.37 for $\varepsilon$. Additionally results achieved with $\mathrm{CO}_{2}$ laser has been compared with other excitation sources such as flash lamp and pulse Nd:YAG laser.

\subsection{Measurements with close up lens}

The measurements with close up $\mathrm{x} 1$ lens were carried out with different laser system parameters: laser power $[\mathrm{W}]$ and scanning speed [m/s]. Although the IFOV for applied optics was about $30 \mu \mathrm{m}$, it allowed observing both artificial and natural defects (figure 7). On the other hand it required to achieve a small distance between the sample and the lens, approximately $33 \mathrm{~mm}$. In the case of macro lens it was possible to detect a crack that was even several $\mu \mathrm{m}$ wide 


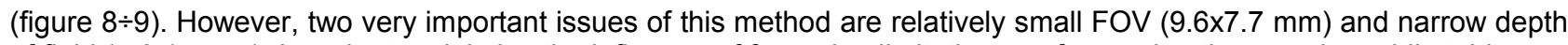
of field $( \pm 0.15 \mathrm{~mm})$. In order to minimize the influence of foregoing limitations as for moving the sample mobile table was developed for the measurement system.

Figures $7 a \div b$ show two defects with high depth to width ratio. Artificial flaw was $60 \mu \mathrm{m}$ wide and $250 \mu \mathrm{m}$ deep, so the ratio was about 4.2 , whereas natural crack was $25 \mu \mathrm{m}$ and $500 \mu \mathrm{m}$ deep, so in this case the ratio was about 20 . Another advantage of depicted defects was that they were perpendicular to the cladding direction.

a)

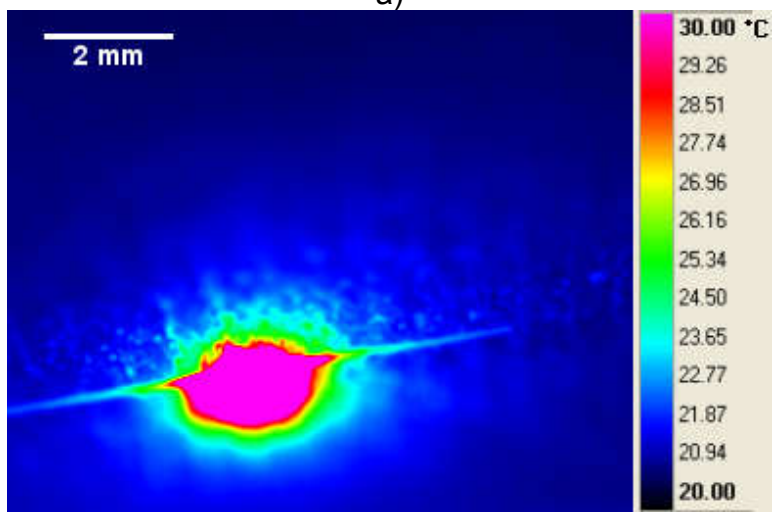

Fig. 7. Observation of $\mathrm{CO} 2$ laser excitation with close up lens: artificial (a) and natural defect (b) b)

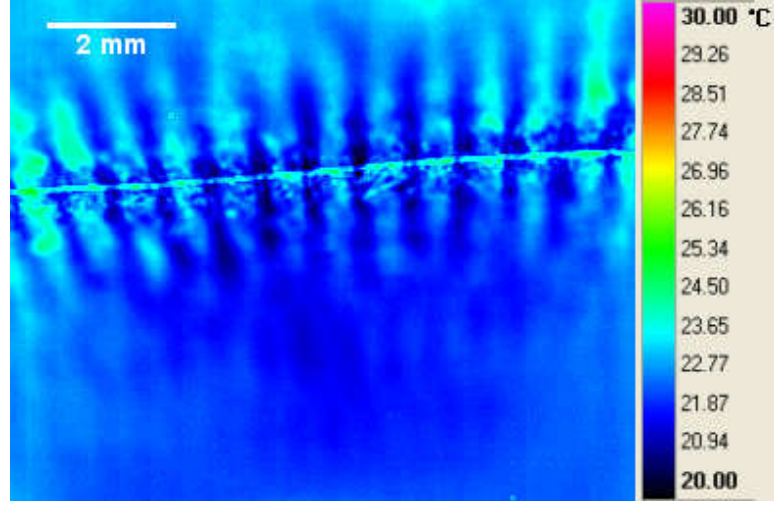

a)

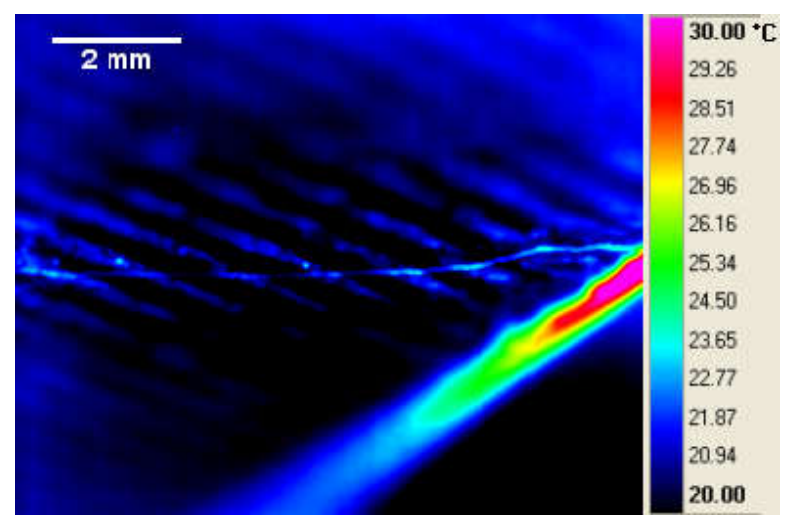

b)

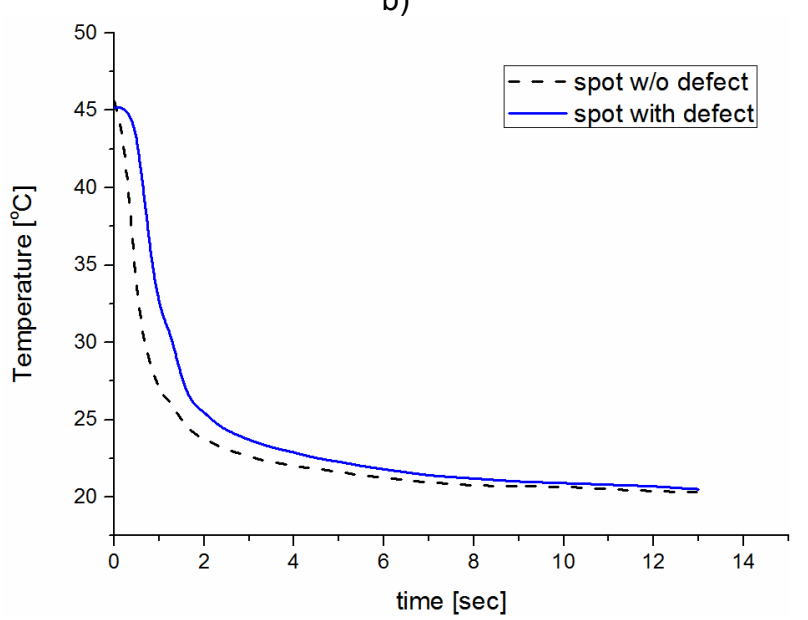

Fig. 8. Thermal image (a) and timing graph (b) for the sample with natural crack excited with CO2 laser (power - 6.25 W, scanning speed - $1 \mathrm{~mm} / \mathrm{s}$ )

Observing much narrower $(10 \mu \mathrm{m})$ and shallow $(15 \mu \mathrm{m})$ natural defects required finding appropriate laser system parameters and this has been done by designed experiment. Two variable parameters were considered: laser power $(6.25,12.5,18.75$ and $25.0 \mathrm{~W})$ and scanning speed $(1.0,5.0$ and $10.0 \mathrm{~mm} / \mathrm{s})$. Figures 8 and 9 depicts exemplary result of this experiment for two parameters set. Not only do these figure show thermal images after the excitation but also temperature timing graph of two points: inside and outside the crack. One can see that for higher laser power the temperature difference between these two spots is much larger for longer period of time. Moreover it should be emphasized that even with slower scanning speed obtained thermograph is characterized by lower defect to background contrast. 
a)

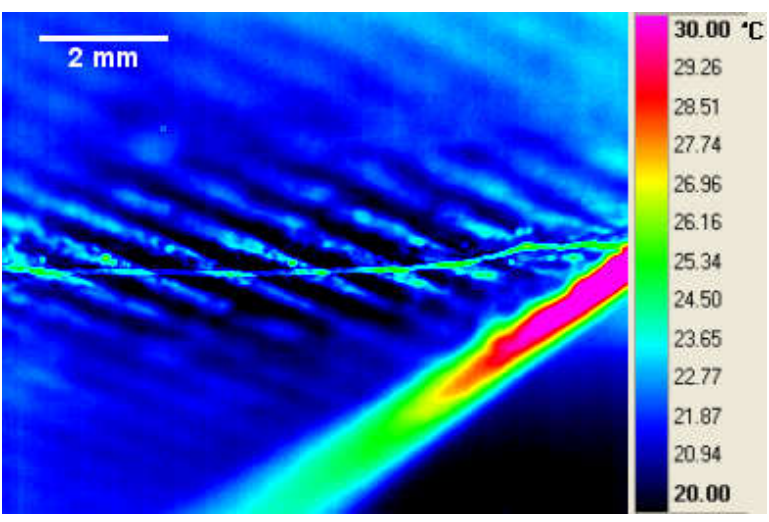

b)

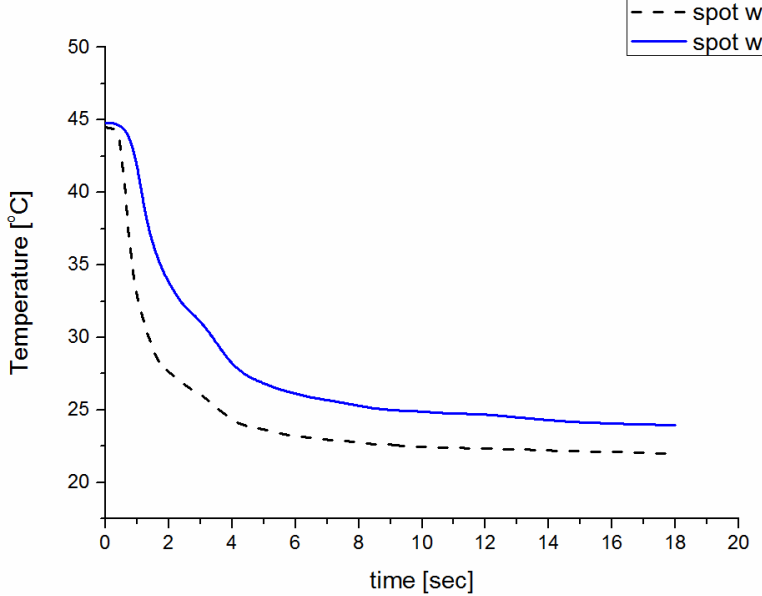

Fig. 9. Thermal image (a) and timing graph (b) for the sample with natural crack excited with CO2 laser (power- $25 \mathrm{~W}$, scanning speed $-5 \mathrm{~mm} / \mathrm{s}$ )

\subsection{Measurements with standard $50 \mathrm{~mm}$ objective}

During tests with thermal camera SC7500 with standard $50 \mathrm{~mm}$ lens the response of the samples after one minute long laser impulse scanning performed in the middle of the coating were measured. The results are shown in figure $10 a \div b$. It should be noticed that all of the artificial defects are visible on the thermograph but only one natural crack can be easily identified. However, in figure 10b one may recognize arc-shaped contours that correspond to relatively narrow and shallow surface cracks on the laser deposited coating. As they depth to width ratio is about 1.5 in contrast to 20.0 of the vertical crack in the bottom of the sample, the emissivity perturbation is much smaller in their case and this results with lesser temperature disturbance. Therefore, for achieved spatial about $160 \mu \mathrm{m}$ resolution these changes are too small to be observed easily.

a)

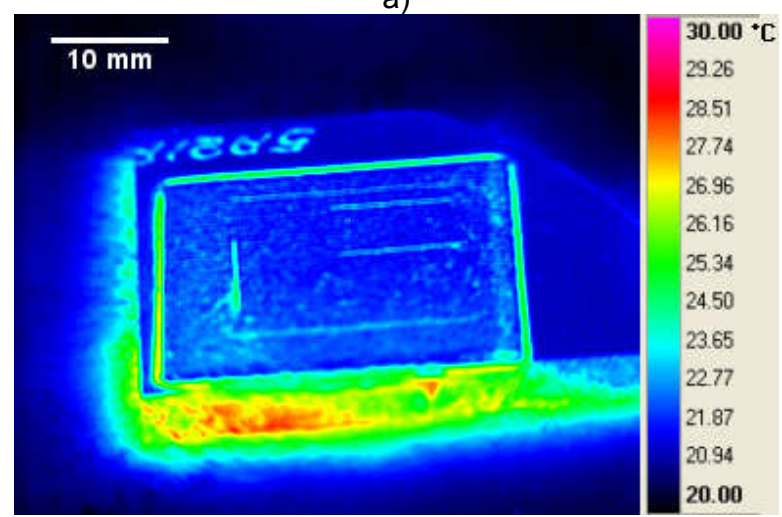

b)

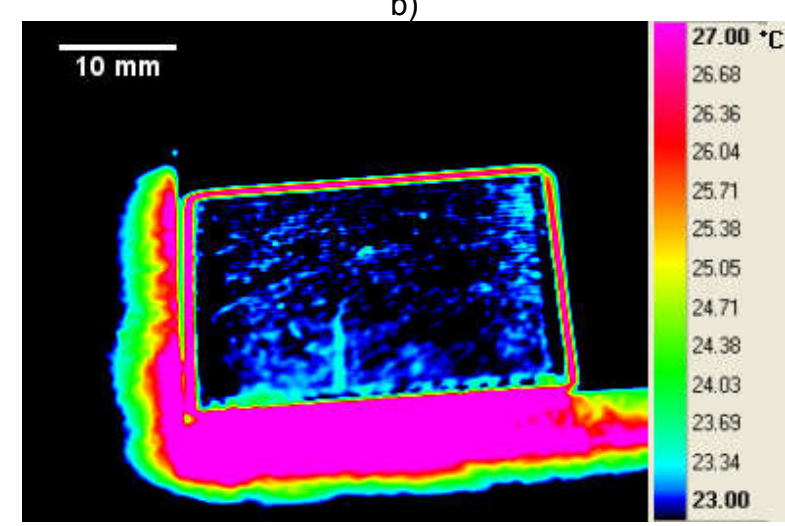

Fig. 10. Step response of the sample with artificial (a) and natural defects (b)

Subsequently another method of excitation has been used for inspected coatings - scanning the whole sample. Scanning speeds used for test were equal 10 and $100 \mathrm{~mm} / \mathrm{s}$. Using higher velocities such as $1 \mathrm{~m} / \mathrm{s}$ demands multiple scans of the surface and might not give better results as metals has relatively high thermal inertia [12]. Besides different strategies for scanning the specimen have been evaluated (figure 11). It is worth mentioning that defects perpendicular to the scanning direction have a higher temperature contrast that those that are parallel. 
a)

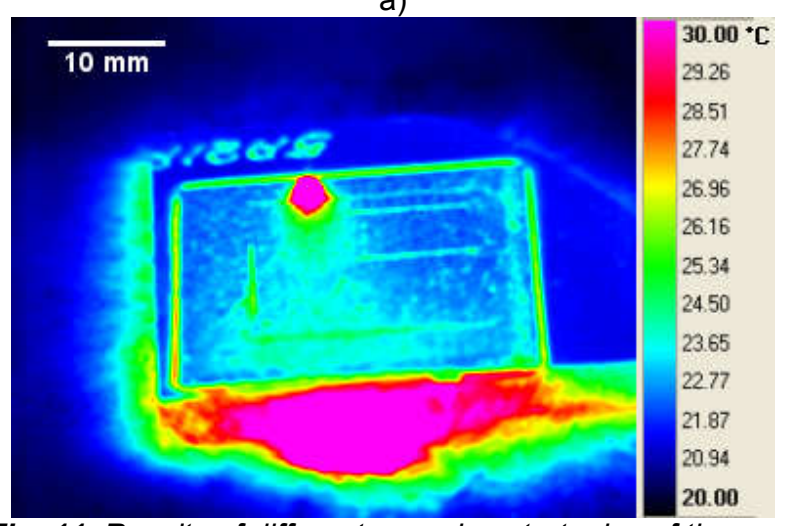

b)

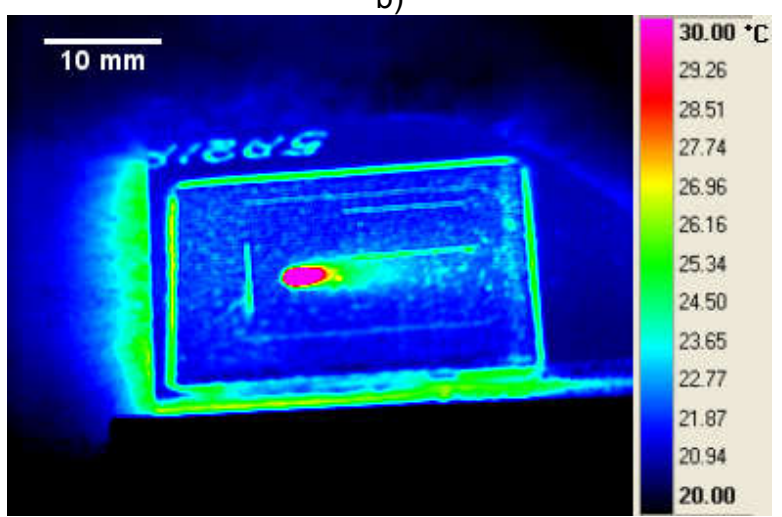

Fig. 11. Results of different scanning strategies of the sample coating with artificial defects: vertically (a) and horizontally (b), scanning speed $-10 \mathrm{~mm} / \mathrm{s}$

Another approach consisted in using additional 0.5 " extension tube in order to achieve larger magnification of the optical system used for camera. However, this action has also a drawbacks discussed earlier. Obtained magnification with extension compared to usage of solely $50 \mathrm{~mm}$ lens was about $\mathrm{x} 2.0$. This means that in this case one pixel of the image depicts the object of size about $80.0 \times 80.0 \mu \mathrm{m}$. Figure $12 \mathrm{a} \div \mathrm{b}$ is showing the same laser deposited coatings that was subjected to the same excitation by $\mathrm{CO}_{2}$ laser spot scanning but one image was obtained when extension ring was used, whereas with the second one it was not.

a)

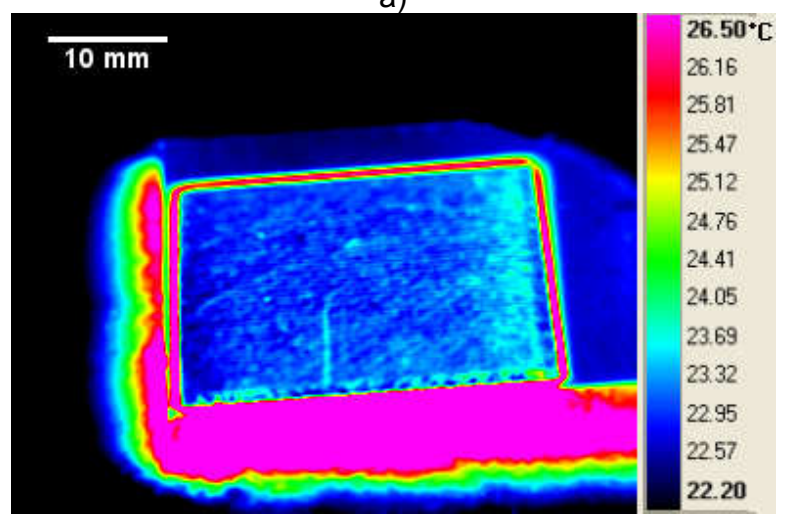

b)

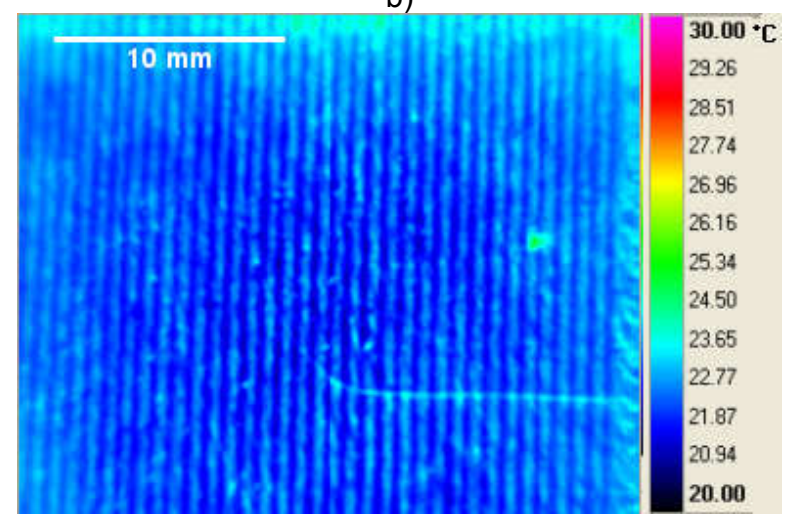

Fig. 12. Result of laser excitation by scanning the whole coating horizontally: with $50 \mathrm{~mm}$ lens (a) and additional extension ring (b)

Nevertheless, the results of using the additional extension ring linked to the standard $50 \mathrm{~mm}$ lens must be considered unpromising. In comparison to macro lens, this approach didn't enable to observe narrow cracks of width about $10 \mu \mathrm{m}$ and depth less than $20 \mu \mathrm{m}$. For example in figure $12 \mathrm{~b}$ the trace of the crack is lost when the depth decrease from 500 to $20 \mu \mathrm{m}$. Moreover the edges of the thermal image are quite indistinct. This seems to be another drawback of this method, since when the object is out of thermal camera focus then it is difficult to measure small temperature disturbances.

\subsection{Comparison of excitation sources}

The final stage of tests of active thermography for inspection of coatings obtained in laser cladding process was comparison of three different excitation sources: constant wave CO2 laser, picosecond pulse Nd:YAG laser and flash lamp. The measurements that were carried out with the flash lamp allowed detection of only artificial defects with width greater than $50 \mu \mathrm{m}$. Moreover as an imaging system only $50 \mathrm{~mm}$ lens could be used, because short working distance of macro lens make it impossible to obtain homogeneous imaging of the entire surface of the sample. Hence, the excitation sources were compared for only one thermal camera lens but slightly different magnifications were achieved because of construction of measurement systems. As a comparative sample laser deposited coating with six artificial arc-shaped defects was used. The width of the flaws was about $30 \mu \mathrm{m}$ and their depth changes from 60 to $200 \mu \mathrm{m}$ from left to right. The figure $13 a \div c$ shows the exemplary outcome of active thermography measurement using mentioned excitation sources. 
a)

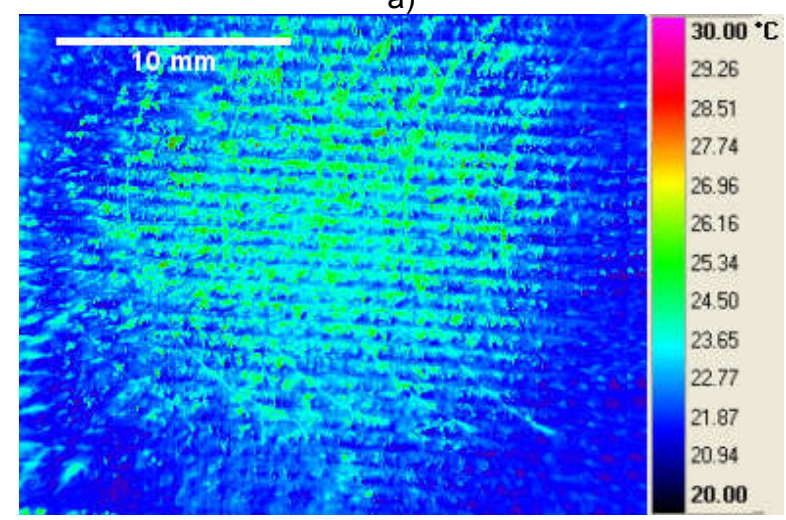

b)

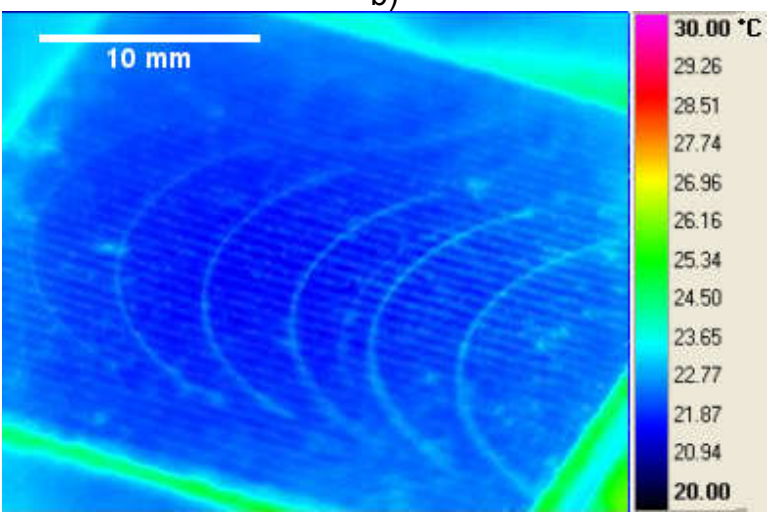

c)

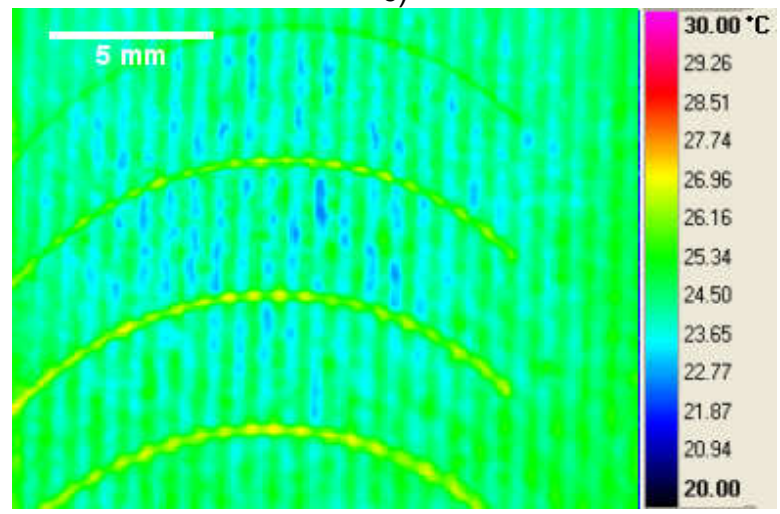

Fig. 13. Comparison of excitation methods for inspection of laser deposited coating with artificial arc-shaped defects: flash lamp 6kJ (a), pulse Nd:YAG laser $15 W$ (b) and $\mathrm{CW} \mathrm{CO}_{2}$ laser 25W (c)

Thermal images that are shown in figure $13 a \div c$ indicates that with flash lamp as excitation source it is not possible to observe all of the defects. Moreover, this kind of excitation is indirect and can cause higher reflection rate than laser spot thermography. The excitation with pulse Nd:YAG laser gives also lower temperature contrast of defects than use of $\mathrm{CO} 2$ laser, since it has lower power and works in pulse mode. However it enables to observe all six arcshaped artificial flaws but as well as with $\mathrm{CO} 2$ laser it is impossible to detect natural micro-cracks.

\section{Conclusions}

The laser spot thermography method was used as an inspection method for finding cracks on laser deposited $\mathrm{NiCrBSi}$ alloy coating. It was shown that the crack depth to width ratio is much better indicator of its detectability via thermographic method than its width. Using flying laser thermography it is possible to detect the flaws that width is smaller than the minimum detectable object size calculated from IFOV. The reason of this fact is that with thermal camera one does not observe the flaws geometry but the temperature field disturbances induced by them.

Using close up $x 1$ lens it was possible to detect cracks with relatively low depth to width ratio about 1 or 2 . On the contrary, standard $50 \mathrm{~mm}$ objective didn't allow observing such defects with appropriate contrast. Neither additionally used extension tube let detect them. However observing flaws with higher depth to width ratio was feasible including artificial defects. Therefore it can be summarized that with described thermal camera and standard $50 \mathrm{~mm}$ lens with extension tubes one can detect micro-cracks larger than $10 \mu \mathrm{m}$ if they depth to width ratio that is respectively high. This means that the cracks behaves as a good absorber and emitter and therefore causes larger emissivity disturbances that can be seen by thermal camera.

Moreover, it was indicated that with laser spot thermography much better contrast of defects can be obtained on thermal images than by using flash lamp. This is caused by selective laser interaction with coating's surface and reduction of reflections that put up the noise level on the image. Comparison of two laser sources: continuous wave $\mathrm{CO}_{2}$ laser and pulse $\mathrm{Nd}$ :YAG laser lead to the conclusion that excitation with higher power and continuous mode seems to be more efficient in flying laser thermography method.

Summing up, flying laser thermography can be used as relatively fast and noninvasive a method of nondestructive testing of laser deposited coatings. However, in order to achieve higher accuracy of detecting the cracks one should use thermal camera with microscope or close up lens. 


\section{REFERENCES}

[1] Baraniecki T., Chlebus E., Dziatkiewicz M., Kędzia J., Reiner J., Wiercioch M., System for laser microsurfacing of metal powders, Welding International - Vol. 30, no. 2 (2016), pp. 98-102, 2016.

[2] Song J., Li Y., Fu J., Deng Q., Hu D., Cracking behavior of laser cladding forming nickel based alloys, Proceedings of International Technology and Innovation Conference 2009, Xian (China), 2009.

[3] Broberg P., Surface crack detection in welds using thermography, NDT \& E International, - Vol. 57, pp. 6973, 2013.

[4] Runnelman A,, Broberg P., Surface crack detection using thermography and ultraviolet excitation, Proceedings of 12th Quantitative InfraRed Thermography conference, paper QIRT2014-016 Bordeaux (France), 2014.

[5] Almond D. P., Weekes B., Li T., Pickering S. G., Kostson E., Wilson J., Tian G. Y., Dixon S., Burrows S., Thermographic techniques for the detection of cracks in metallic components, Insight: Non-Destructive Testing and Condition Monitoring, - Vol. 53, no. 11 (2011), pp. 614-620, 2011.

[6] Maillard S., Cadith J., Eschimese D., Walaszek H., Mooshofer H., Candore J.C., Bodnar J.L., Towards the use of passive and active infrared thermography to inspect metallic components in the mechanical industry, Proceedings of 10th Quantitative InfraRed Thermography conference, paper QIRT2010-126 Québec (Canada), 2010.

[7] Meola C., Carlomagno G. M., Squillace A., Vitiello A., Non-destructive evaluation of aerospace materials withlock-in thermography, Engineering Failure Analysis - Vol. 13, no. 3(2006), pp. 380-388, 2006.

[8] C. Ibarra-Castanedoa, N. P. Avdelidisb, M. Greniera, X. Maldaguea and A. Bendada, Active thermography signal processing techniques for defect detection and characterization on composite materials, Proceedings of SPIE - The International Society for Optical Engineering 7661, 2011.

[9] Roemer J., Pieczonka Ł., Uhl T., Laser spot thermography of welded joints, Diagnostyka - Vol. 15, no. 2 (2014), pp. 43-49, 2014.

[10] Netzelmann U., Walle G., Thermographic Crack Detection in Ferritic Steel Components Using Inductive Heating, Proceedings of 9th European Conference on Non Destructive Testing, paper Tu.4.8.5 Berlin (Germany), 2006.

[11] Schlichting J., Ziegler M., Maierhofer Ch., Kreutzbruck M., Flying Laser Spot Thermography for the Fast Detection of Surface Breaking Cracks, Proceedings of 18th World Conference on Nondestructive Testing, Durban (South Africa), 2012.

[12] Burrows S. E., Dixon S., Pickering S. G., Li T., Almond D. P., Thermographic detection of surface breaking defects using a scanning laser source, NDT \& E International - Vol. 44, no. 7 (2011), pp. 589-596, 2011.

[13] Więcek B., De Mey G., Termowizja w podczerwieni Podstawy i zastosowania, Wydawnictwo PAK, Gliwice (Poland), 2011.

[14] Modest M. F., Radiative Heat Transfer, $2^{\text {nd }}$ Edition, Academic Press Elsevier Science (USA), 2003.

[15] Michalski L., Eckersdorf K., Kucharski J., McGhee J., Temperature Measurment, $2^{\text {nd }}$ Edition, John Wiley \& Sons, Chichester (England), 2001.

[16] Reiner J., Identyfikacja i modelowanie optyczne systemów wizyjnej kontroli jakości wytwarzania, Oficyna Wydawnicza Politechniki Wrocławskiej, Wrocław, 2013.

[17] Kałuża M., Więcek B., De Mey G., The use of extension tubes in thermography, Proceedings of 10th Quantitative InfraRed Thermography conference, paper QIRT2010-063 Québec (Canada), 2010.

[18] Vollmer M., Möllm9ann K. P., Infrared Thermal Imaging: Fundamentals, Research and Applications, WileyVCH Verlag, Weinheim (Germany), 2010. 